\title{
Regional Differences in Extracellular Dopamine and Serotonin Assessed by In Vivo Microdialysis in Mice Lacking Dopamine and/or Serotonin Transporters
}

\author{
Hao-wei Shen', Yoko Hagino', Hideaki Kobayashi', Keiko Shinohara-Tanaka', Kazutaka Ikeda', \\ Hideko Yamamoto', Toshifumi Yamamoto ${ }^{2}$, Klaus-Peter Lesch ${ }^{3}$, Dennis L Murphy ${ }^{4}$, F Scott Hall ${ }^{5}$, \\ George R UhI ${ }^{5}$ and Ichiro Sora*,1,5,6 \\ 'Department of Molecular Psychiatry, Tokyo Institute of Psychiatry, Japan; '2Laboratory of Molecular Recognition, Graduate School of Integrated \\ Science, Yokohama City University, Japan; ${ }^{3}$ Department of Psychiatry and Psychotherapy, University of Wurzburg, Germany; ${ }^{4}$ Laboratory of \\ Clinical Science, Intramural Research Program, National Institute of Mental Health, USA; ${ }^{5}$ Molecular Neurobiology Branch, Intramural Research \\ Program, National Institute on Drug Abuse, USA; ${ }^{\circ}$ Division of Psychobiology, Department of Neuroscience, Tohoku University Graduate School of \\ Medicine, Japan
}

\begin{abstract}
Cocaine conditioned place preference (CPP) is intact in dopamine transporter (DAT) knockout (KO) mice and enhanced in serotonin transporter (SERT) KO mice. However, cocaine CPP is eliminated in double-KO mice with no DAT and either no or one SERT gene copy. To help determine mechanisms underlying these effects, we now report examination of baselines and drug-induced changes of extracellular dopamine $\left(\mathrm{DA}_{\mathrm{ex}}\right)$ and serotonin $\left(5-\mathrm{HT}_{\mathrm{ex}}\right)$ levels in microdialysates from nucleus accumbens (NAc), caudate putamen (CPu), and prefrontal cortex (PFc) of wild-type, homozygous DAT- or SERT-KO and heterozygous or homozygous DAT/SERT double$\mathrm{KO}$ mice, which are differentially rewarded by cocaine. Cocaine fails to increase DA ex in NAc of DAT-KO mice. By contrast, systemic cocaine enhances DA $\mathrm{ex}_{\mathrm{x}}$ in both CPu and PFc of DAT-KO mice though local cocaine fails to affect DA ex $_{\text {in }}$ CPu. Adding SERT to DAT deletion attenuates the cocaine-induced $\mathrm{DA}_{\text {ex }}$ increases found in $\mathrm{CPu}$, but not those found in PFc. The selective SERT blocker fluoxetine

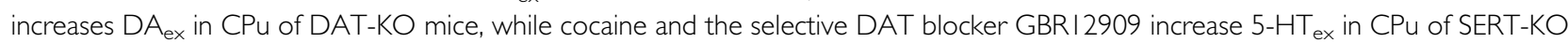

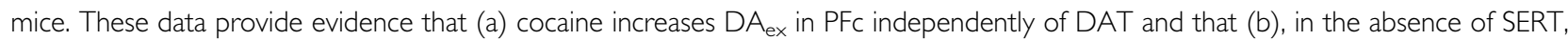
CPu levels of 5-HT ex can be increased by blocking DAT. Cocaine-induced alterations in CPu DA levels in DAT-, SERT-, and DAT/SERT double-KO mice appear to provide better correlations with cocaine CPP than cocaine-induced DA level alterations in NAc or PFc. Neuropsychopharmacology (2004) 29, 1790-1799, advance online publication, 30 June 2004; doi: I 0. I 038/sj.npp. 1300476
\end{abstract}

Keywords: dopamine; serotonin; monoamine transporter; cocaine reward; knockout mice; in vivo microdialysis

\section{INTRODUCTION}

Cocaine increases extracellular levels of dopamine (DA), serotonin (5-HT) and norepinephrine (NE) by blocking the neural plasma membrane transporters for those neurotransmitters. Increased extracellular DA $\left(\mathrm{DA}_{\mathrm{ex}}\right)$ levels in mesocorticolimbic DA systems have been postulated to mediate cocaine reward (Kuhar et al, 1991; Koob and Nestler, 1997; Bardo, 1998; Kelley and Berridge, 2002). However, homozygous dopamine transporter (DAT) knockout $(\mathrm{KO})$ mice (DAT-I- mice) express intact cocaine

\footnotetext{
*Correspondence: Dr I Sora, Division of Psychobiology, Department of Neuroscience, Tohoku University Graduate School of Medicine, I-I Seiryo-machi, Sendai 980-8574, Japan, Tel: + 8I 22717 7808, Fax: +81 22717 7809, E-mail: isora@mail.cc.tohoku.ac.jp

Received 2 July 2003; revised 25 March 2004; accepted 29 March 2004 Online publication: 6 April 2004 at http://www.acnp.org/citations/ Npp04060403295/default.pdf
}

reward in conditioned place preference (CPP) (Sora et al, 1998) and drug self-administration paradigms (Rocha et al, 1998). Cocaine reward is eliminated in double-KO mice with no DAT gene copies and either no or one copy of the SERT gene (Sora et al, 2001), but not in double-KO mice with neither DAT nor NET gene copies (Hall et al, 2002). Further, serotonin transporter (SERT) blockade with fluoxetine or norepinephrine transporter (NET) blockade with nisoxetine can yield rewarding effects in DAT-KO mice, which are never seen in wild-type animals (Hall et al, 2002).

We and others have postulated that the retention of cocaine reward in DAT-KO mice may be due to (a) roles for non-DA systems in normal cocaine reward and (b) adaptations to the lifelong loss of DAT found in DAT-KO mice (Kirkpatrick, 2001; Sora et al, 2001; Uhl et al, 2002). Some of these adaptive changes could come from involvement of redundant monoaminergic systems in cocaine 
reward. Since each transporter displays significant affinities for each monoamine (Faraj et al, 1994; Giros et al, 1994; Gu et al, 1994; Eshleman et al, 1999), the absence of its cognate transporter might allow a monoamine to diffuse further from its site of release and be accumulated by another transporter.

Cocaine and selective norepinephrine transporter (NET) blockers (eg reboxetine) are each reported to increase $\mathrm{DA}_{\mathrm{ex}}$ in NAc of DAT-KO mice, suggesting that NET could act as an alternative uptake site for DA in such animals and that NET blockade might be a mechanism for both the cocaineand nisoxetine-induced rewards found in DAT-KO mice (Carboni et al, 2001; Hall et al, 2002). However, in vitro data fail to identify cocaine influences on $\mathrm{CPu}$ or NAc DA uptake in DAT-KO mice (Budygin et al, 2002; Moron et al, 2002). The simple idea that NET mediates cocaine reward in the absence of DAT is also incompatible with observations that cocaine reward is ablated in DAT/SERT double-KO mice that express normal levels of NET (Sora et al, 2001).

Roles for 5-HT systems in cocaine reward (or aversion) are also less than clear from current data (Cunningham and Callahan, 1991; Kleven et al, 1995; Rocha et al, 1997; Kleven and Koek, 1998; Lee and Kornetsky, 1998; Parsons et al, 1998; Shippenberg et al, 2000; Baker et al, 2001; SasakiAdams and Kelley, 2001). Homozygous SERT-KO mice display enhanced cocaine CPP that is increased even more in combined SERT/NET double-KO mice (Sora et al, 1998; Hall et al, 2002). SERT-KO mice, in themselves and in combination with DAT-KOs, thus provide interesting models in which to investigate 5-HT, DA, and 5-HT/DA interactions important for psychostimulant reward.

In this present study, we have therefore examined baselines and drug-induced changes of $\mathrm{DA}_{\mathrm{ex}}$ and $5-\mathrm{HT}_{\mathrm{ex}}$ in several brain regions implicated in psychostimulant effects, the NAc, CPu and prefrontal cortex (PFc) in DATKO, SERT-KO, and both heterozygous and homozygous DAT/SERT double-KO mice. We have studied the effects of both the nonselective blocker cocaine and the selective SERT and DAT blockers fluoxetine and GBR12909. These investigations provide insights into adaptive processes found in these mice and into 5-HT, DA, and 5-HT/DA interactions of the possible importance for cocaine reward.

\section{MATERIALS AND METHODS}

\section{Animals}

Mutant mice lacking DAT, SERT, and littermate wild-type mice were obtained from heterozygote crosses on 129/C57 mixed genetic backgrounds. DAT/SERT double-KO mice were obtained by intercrossing single KO lines as described previously (Sora et al, 2001). DNA extracted from tail biopsies was genotyped using PCR. Mice were grouphoused (two to four per cage) with food and water ad libitum in a room maintained at $22 \pm 2^{\circ} \mathrm{C}$ and $65 \pm 5 \%$ humidity under a $12 \mathrm{~h}$ light-dark cycle. Male and female mice from 10-24 weeks old of each genotype group (nequals;4-8) were used in each experiment equally. All animal experiments were performed in accordance with the Guidelines for the Care of Laboratory Animals of the Tokyo Institute of Psychiatry.
For the $\mathrm{CPu}$ cocaine study, all the nine $\mathrm{DAT} \times \mathrm{SERT}$ genotypes were examined $(\mathrm{DAT}+I+\mathrm{SERT}+I+, \mathrm{DAT}+I+$ $\mathrm{SERT}+l-, \quad \mathrm{DAT}+I+\mathrm{SERT}-l-, \quad \mathrm{DAT}+I-\mathrm{SERT}+I+$, $\mathrm{DAT}+I-\mathrm{SERT}+l-, \quad$ DAT $+I-\mathrm{SERT}-l-, \quad$ DAT $-I-$ SERT $+l+$, DAT $-l-$ SERT $+/-$, and DAT $-/-$ SERT $-l-$ ). For NAc and PFc cocaine studies and for fluoxetine $\mathrm{CPu}$ and NAc studies, the four homozygous genotypes were examined (wildtype, DAT $-I-\mathrm{SERT}+I+$, DAT + I + SERT $-I-$, DAT-/-SERT-/-). GBR12909 effects on CPu 5-HT ${ }_{\text {ex }}$ levels were examined in wild-type and DAT $+I+$ SERT $-I-$ mice.

\section{Surgery}

Mice were stereotaxically implanted with microdialysis probes under sodium pentobarbital anesthesia $(50 \mathrm{mg} / \mathrm{kg})$ in $\mathrm{CPu}$ (anterior $+0.6 \mathrm{~mm}$, lateral $+1.8 \mathrm{~mm}$ ventral $-4.0 \mathrm{~mm}$ from bregma), NAc (anterior $+1.2 \mathrm{~mm}$, lateral $+1.0 \mathrm{~mm}$ ventral $-5.0 \mathrm{~mm}$ from bregma) or PFc (anterior $+2.0 \mathrm{~mm}$, lateral $+0.5 \mathrm{~mm}$ ventral $-3.0 \mathrm{~mm}$ from bregma) according to the atlas of Franklin and Paxinos (1997). Probe tips were constructed with regenerated cellulose membranes that provided $50 \mathrm{kDa}$ molecular weight cutoffs, outer diameters of $0.22 \mathrm{~mm}$, and membrane lengths of either $1 \mathrm{~mm}$ (NAc) or $2 \mathrm{~mm}$ (CPu and PFc) (Eicom, Kyoto, Japan). Dialysis probe placements were verified histologically at the ends of each experiment (Figure 1), and experimental data were excluded if the membrane portions of the dialysis probes lay outside the central $\mathrm{CPu}$, medial $\mathrm{PFc}$ or NAc core or shell regions, respectively.

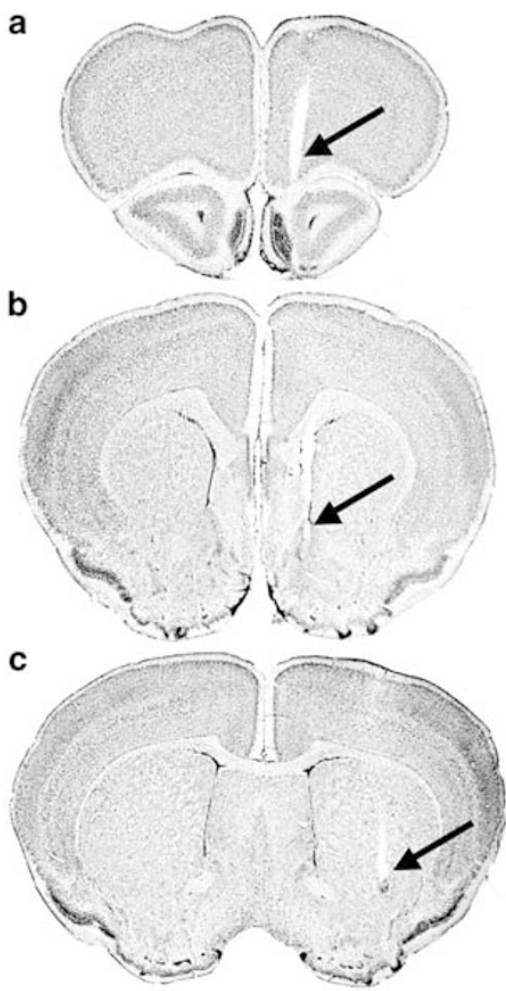

Figure I Location of dialysis probes in coronal sections of PFc (a), NAc (b), and $\mathrm{CPu}$ (c). The arrows illustrate the implantation sites of dialysis probes. 


\section{Microdialysis and Analytical Procedure}

At $24 \mathrm{~h}$ after implantation, probes in freely moving mice were perfused with Ringer's solution $\left(147 \mathrm{mM} \mathrm{Na}^{+}, 4 \mathrm{mM}\right.$ $\mathrm{K}^{+}, 1.26 \mathrm{mM} \mathrm{Ca}^{2+}, 1 \mathrm{mM} \mathrm{Mg}^{2+}$, and $152.5 \mathrm{mM} \mathrm{Cl}^{-}, \mathrm{pH}$ 6.5) at $1 \mu \mathrm{l} / \mathrm{min}$ for $180 \mathrm{~min}$. $\mathrm{DA}_{\mathrm{ex}}$ and $5-\mathrm{HT}_{\mathrm{ex}}$ baselines were obtained from average concentrations of three consecutive $10 \mathrm{~min}, 10 \mu \mathrm{l}$ samples. These and subsequent $10 \mathrm{~min}, 10 \mu \mathrm{l}$ dialysate fractions were analyzed using an AS-10 autoinjector (Eicom), high-performance liquid chromatography (HPLC), with a PPS-ODS reverse-phase column (Eicom) and a ECD-100 graphite electrode detector (Eicom). The mobile phase consisted of $0.1 \mathrm{M}$ phosphate buffer ( $\mathrm{pH}$ 5.5) containing sodium decanesulfonate $(500 \mathrm{mg} / \mathrm{l})$, EDTA $(50 \mathrm{mg} / \mathrm{l})$, and $1 \%$ methanol. Detection limits for DA and 5 -HT were $1 \mathrm{fmol} / \mathrm{sample}$ with signal-to-noise ratios of at least 2 . In vitro recoveries from the 1 - and 2-mm membrane length probes were 10 and $15 \%$, respectively.

\section{Drugs}

Test drugs were dissolved in saline for systemic administration or in Ringer's solution for local infusion via microdialysis probes. After establishment of stable baselines, cocaine $\mathrm{HCl}(10 \mathrm{mg} / \mathrm{kg}$ for subcutaneous injection or $100 \mu \mathrm{M}$ for local infusion; Dainippon, Osaka, Japan), fluoxetine $(20 \mathrm{mg} / \mathrm{kg}$, Sigma, Tokyo, Japan), GBR12909 $(10 \mathrm{mg} / \mathrm{kg}$, Sigma) or saline $(10 \mathrm{ml} / \mathrm{kg})$ was administered subcutaneously (s.c.) and dialysates collected for 3 or $2 \mathrm{~h}$, respectively.

\section{Statistics}

Baselines of $\mathrm{DA}_{\mathrm{ex}}$ and $5-\mathrm{HT}_{\mathrm{ex}}$ were compared across genotype groups using two-way ANOVAs (DAT genotype, and SERT genotype). DA and 5-HT responses to drugs were expressed as percentages of baselines. Effects of drugs on $\mathrm{DA}_{\mathrm{ex}}$ and $5-\mathrm{HT}_{\mathrm{ex}}$ were assessed by calculating the areas under time-response curves (AUC) for the first 120 or $180 \mathrm{~min}$ after drug administration. AUCs were analyzed using two-way ANOVAs (Drug, Genotype). Least significant difference tests were applied for multiple comparisons and $P$-values less than 0.05 were considered statistically significant. Statistical analyses used STATISTICA (StatSoft Inc., Tulsa, OK).

\section{RESULTS}

Baselines of $\mathrm{DA}_{\mathrm{ex}}$ and $5-\mathrm{HT}_{\mathrm{ex}}$ in $\mathrm{CPu}, \mathrm{NAc}$, and PFc

The mean $( \pm \mathrm{SEM})$ baselines of $\mathrm{DA}_{\mathrm{ex}}$ and $5-\mathrm{HT}_{\mathrm{ex}}$ in dialysates from the $\mathrm{CPu}, \mathrm{NAc}$, and $\mathrm{PFc}$ in mice, who were subsequently treated with either vehicle or test drugs, are shown in Table 1. Two-way ANOVA of $\mathrm{DA}_{\mathrm{ex}}$ baselines confirmed that DAT-KO had significant effects on $\mathrm{DA}_{\mathrm{ex}}$ baselines in $\mathrm{CPu}(\mathrm{F}(1,91)=299.77, P<0.00001)$ and NAc $(\mathrm{F}(1,55)=101.49, P<0.00001)$, but not $\operatorname{PFc}(\mathrm{F}(1,33)=0.07$, $P=0.79$ ). Dialysate DA in homozygous DAT-KO mouse $\mathrm{CPu}$ and NAc was approximately 10 -fold higher than that in mice with either one or two copies of the DAT gene. $5-\mathrm{HT}_{\mathrm{ex}}$ baselines were unaffected by DAT-KO in any region.

SERT-KO exerted significant effects on $5-\mathrm{HT}_{\mathrm{ex}}$ baselines in each of these three regions $(\mathrm{F}(2,91)=87.06, P<0.00001$; $\mathrm{F}(1,55)=29.95, P<0.00001 ; \mathrm{F}(1,33)=80.37, P<0.00001$, respectively). In $\mathrm{CPu}, \mathrm{NAc}$, and $\mathrm{PFc}, 5-\mathrm{HT}_{\text {ex }}$ baselines in mice with no SERT gene were six to ten times as large as that found in mice with one or two copies of SERT gene. $\mathrm{DA}_{\text {ex }}$ baselines were unaffected by SERT-KO in any region.

Interestingly, there was a significant interaction between DAT and SERT genotype effects on basal NAc dialysate DA levels $(\mathrm{F}(12,55)=4.33, P<0.05)$. $\mathrm{DA}_{\mathrm{ex}}$ levels in NAc of mice with no DAT or SERT genes (DAT-/-SERT-l-) were higher than those of mice with no DAT genes but two SERT genes $(\mathrm{DAT}-I-\mathrm{SERT}+I+)$.

\section{Systemic Cocaine Effects on $\mathrm{DA}_{\mathrm{ex}}$ in $\mathrm{CPu}, \mathrm{NAc}$, and PFc}

$\mathrm{DA}_{\text {ex }}$ level changes in $\mathrm{CPu}, \mathrm{NAc}$, and $\mathrm{PFc}$ following systemic cocaine administration are shown in Figure 2a, c, and e. DA responses to cocaine in the $\mathrm{CPu}$ of wild-type and $\mathrm{DAT}+I-$ mice peak at 40-60 min (Figure 2a). Cocaine also induces a slower DA response curve in the $\mathrm{CPu}$ of homozygous

Table I The Baselines (fmol//O min) of DA ex and 5-HTex in CPu, NAc and PFc

\begin{tabular}{|c|c|c|c|c|c|c|c|c|c|c|}
\hline \multicolumn{2}{|c|}{ Genotype } & \multicolumn{3}{|c|}{$\mathrm{CPu}$} & \multicolumn{3}{|c|}{ NAc } & \multicolumn{3}{|c|}{ PFc } \\
\hline DAT & SERT & $n$ & DA & 5-HT & $n$ & DA & $5-\mathrm{HT}$ & $n$ & DA & $5-\mathrm{HT}$ \\
\hline$+/+$ & $+1-$ & 8 & $82.28 \pm 13.76$ & $2.39 \pm 0.29$ & - & - & - & - & - & - \\
\hline$+/+$ & $-1-$ & 13 & $69.82 \pm 7.12$ & $16.33 \pm 2.58^{*,+}$ & 15 & $16.23 \pm 2.23$ & $15.50 \pm 4.20 *$ & 9 & $2.52 \pm 0.35$ & $25.55 \pm 3.18 *$ \\
\hline$+1-$ & $-1-$ & 9 & $93.04 \pm 14.09$ & $17.73 \pm 3.30^{*}++$ & - & - & - & - & - & - \\
\hline$-1-$ & $+/+$ & 15 & $687.18 \pm 58.16^{*, \#}$ & $1.61 \pm 0.10$ & 14 & $188.17 \pm 23.00 *$ & $1.19 \pm 0.43$ & 9 & $2.32 \pm 0.32$ & $3.28 \pm 0.47$ \\
\hline$-1-$ & $+1-$ & 9 & $667.67 \pm 42.39^{*, \#}$ & $2.38 \pm 0.31$ & - & - & - & - & - & - \\
\hline$-1-$ & $-1-$ & 9 & $548.78 \pm 31.42^{*, \#}$ & $12.78 \pm 1.46^{*},+$ & 14 & $275.34 \pm 38.47^{*}, \&$ & $13.42 \pm 2.36 *$ & 9 & $2.22 \pm 0.15$ & $17.06 \pm 2.61 *$ \\
\hline
\end{tabular}

$\mathrm{DA}_{\text {ex }}$ or $5-\mathrm{HT}_{\text {ex }}$ baselines were obtained from average concentrations ( $\mathrm{fmol} / \mathrm{l} 0 \mathrm{~min}$ ) of three consecutive stable samples before injections. Values are the mean ( \pm SEM) of baselines. $* P<0.000$ I compared to wild-type mice; ${ }^{\#} P<0.000$ I compared to mice with one copy of DAT gene; ${ }^{+} P<0.000$ I compared to mice with one copy of SERT gene; ${ }^{\&} P<0.00$ I compared to DAT $-1-$ mice. 

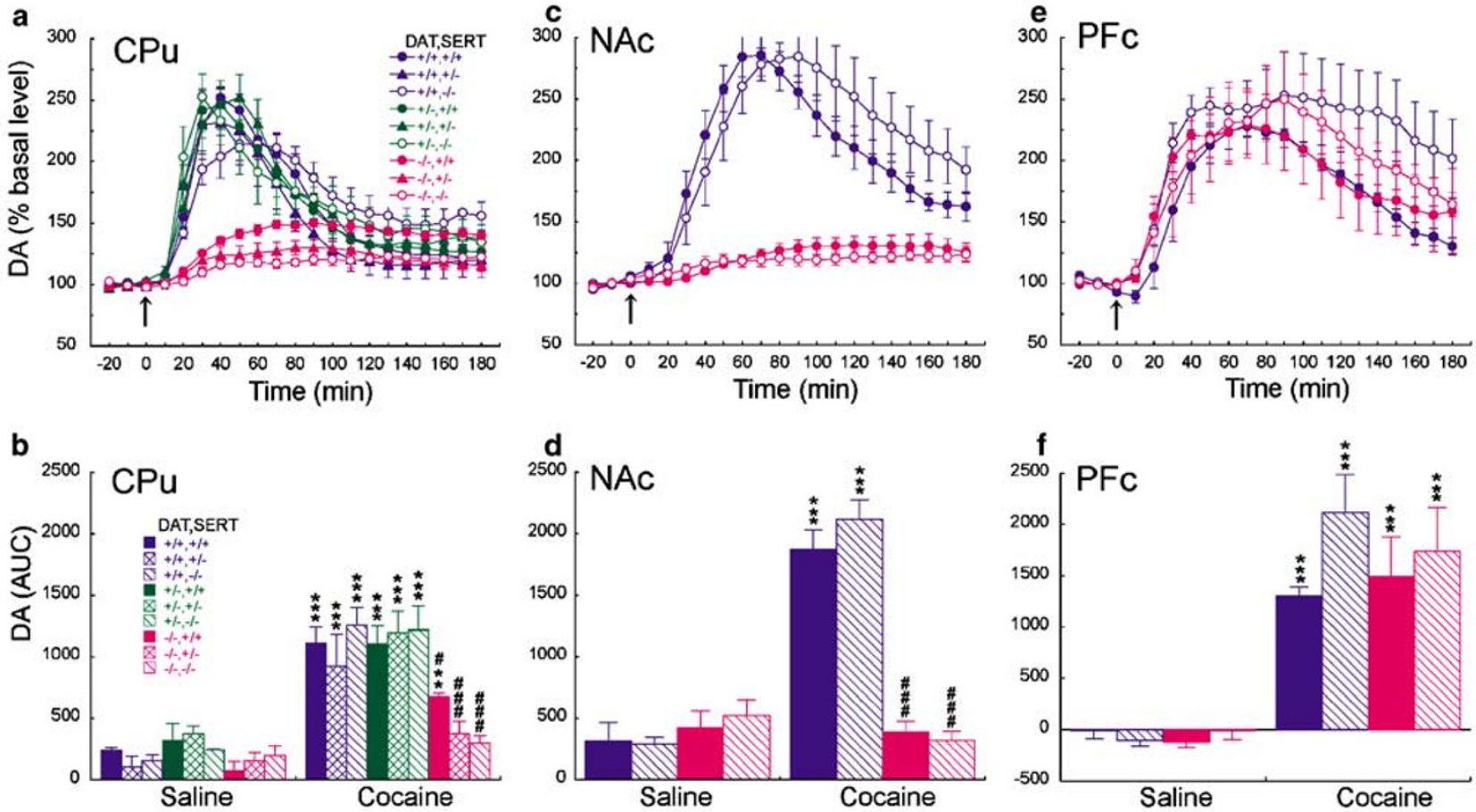

Figure 2 (a, c, and e) Temporal pattern of DA response to cocaine $(10 \mathrm{mg} / \mathrm{kg}$, s.c.) in CPu, NAc, and PFc, respectively. Each point represents the mean $\left( \pm\right.$ SEM) of the percentage of DA $\mathrm{ex}_{\mathrm{b}}$ baselines. The time of injections is indicated with an arrow. $(b, d$, and $f)$ Histogram represents the mean AUC ( \pm SEM) of DA response to saline or cocaine in $\mathrm{CPu}, \mathrm{NAc}$, and PFc during 180 min interval after injection. $* * P<0.01$, $* * * P<0.001$ compared to the saline group of the same genotype; ${ }^{\#} P<0.05,{ }^{\# \#} P<0.00$ I compared to the cocaine-treated wild-type group.

DAT-KO mice (DAT- $/$-SERT $+/+$ ), peaking at about 90 min (Figure 2a). This pattern is not observed in NAc, where DAT $-I-$ SERT $+I+$ mice do not exhibit any larger increments in $\mathrm{DA}_{\mathrm{ex}}$ levels (Figure 2c). In further contrast, wild-type, DAT- - -SERT $+/+$, and DAT $-/-$ SERT $-I-$ mice each exhibit indistinguishable cocaine-induced DA responses in PFc (Figure 2e).

Drug effects on $\mathrm{DA}_{\text {ex }}$ levels can be assessed by studying AUCs (Figure $2 b, d$, and $f$ ). ANOVAs of mean AUC ( \pm SEM) for drug effects on $\mathrm{DA}_{\mathrm{ex}}$ levels reveal that drugs have significant effects on DA AUC in $\mathrm{CPu}(\mathrm{F}(1,62)=132.32$, $P<0.0001)$, NAc $(\mathrm{F}(1,34)=80.60, P<0.0001)$, and $\mathrm{PFc}$ $(\mathrm{F}(1,28)=67.59, \quad P<0.0001)$. Genotype and drug $\times$ genotype interactions were significant for DA AUC in $\mathrm{CPu}$ $(\mathrm{F}(8,62)=5.45, P<0.0001 ; \mathrm{F}(8,62)=3.41, P<0.01$; respectively) and $\mathrm{NAc}(\mathrm{F}(3,34)=23.82, P<0.0001 ; \mathrm{F}(3,34)=$ 36.09, $P<0.0001$; respectively), but not in $\operatorname{PFc}(F(3,28)=$ $0.89, \quad P=0.46 ; \quad \mathrm{F}(3,28)=0.94, \quad P=0.43 ; \quad$ respectively). In $\mathrm{CPu}$ (Figure 2b), DAT-KO mice exhibit statistically significant cocaine-induced increments in $\mathrm{DA}_{\mathrm{ex}}$ levels, although these increases are less than those found in wildtype mice. By contrast, in DAT- - SERT $+I-$ and DAT-I-SERT $-/-$ mice, the same genotypes that do not exhibit rewarding effects of cocaine also do not exhibit cocaine-induced increases in $\mathrm{DA}_{\mathrm{ex}}$ in $\mathrm{CPu}$. No significant differences are observed in cocaine-induced DA AUC increases in $\mathrm{CPu}$ between the $\mathrm{DAT}+I+$ and $\mathrm{DAT}+I-$ mice. In NAc (Figure 2d), cocaine fails to increase $\mathrm{DA}_{\mathrm{ex}}$ in $\mathrm{DAT}-I-\mathrm{SERT}+I+$ or in DAT $-/-\mathrm{SERT}-/-$ mice. There are no significant differences in cocaine-induced DA increases in NAc between wild-type and DAT $+I+$
SERT-I- mice. In PFc (Figure 2f), cocaine produces significant increases in $\mathrm{DA}_{\mathrm{ex}}$ in all genotypes.

\section{Systemic Cocaine Effects on $5-\mathrm{HT}_{\mathrm{ex}}$ in $\mathrm{CPu}, \mathrm{NAc}$, and PFc}

The temporal patterns of $5 \mathrm{HT}$ responses to cocaine in $\mathrm{CPu}$, $\mathrm{NAc}$, and PFc are shown in Figure 3a, c, and e. DAT $+I+$ SERT $-I-$ and DAT $+I-$ SERT $-I-$ mice show gradual $5 \mathrm{HT}$ responses to cocaine in $\mathrm{CPu}$ (Figure 3a) and NAc (Figure 3c), but not in PFc (Figure 3e). 5-HT response curves produced by cocaine are observed in $\mathrm{CPu}$ (Figure 3a) and NAc (Figure 3c) in all genotypes except DAT-1SERT $-I-$ mice. The peak of 5-HT response are smaller for SERT $-I-$ mice than for either SERT $+I+$ or SERT $+I-$ mice. SERT $-I-$ mice exhibit no 5 -HT response to cocaine in PFc (Figure 3c), while wild-type mice exhibit robust increases.

Drug effects on 5- $\mathrm{HT}_{\mathrm{ex}}$ levels are expressed as mean AUC $( \pm$ SEM) in Figure $3 \mathrm{~b}, \mathrm{~d}$, and f. Two-way ANOVAs of the AUC for 5-HT responses to cocaine show significant effects of Drug, Genotype, and Drug $\times$ Genotype interactions in $\mathrm{CPu}(\mathrm{F}(1,62)=181.49, P<0.0001 ; \mathrm{F}(8,62)=5.01$, $P<0.0001 ; \mathrm{F}(8,62)=4.88, P<0.0001 ;$ respectively), NAc $(\mathrm{F}(1,34)=31.57, \quad P<0.0001 ; \quad \mathrm{F}(3,34)=6.44, \quad P<0.0001$; $\mathrm{F}(3,34)=8.41, \quad P<0.0001 ; \quad$ respectively) and $\quad \mathrm{PFc}$ $(\mathrm{F}(1,28)=57.74, \quad P<0.0001 ; \quad \mathrm{F}(3,28)=11.55, \quad P<0.0001$; $\mathrm{F}(3,28)=15.59, \quad P<0.0001 ; \quad$ respectively). In $\mathrm{CPu}$ (Figure 3b) and NAc (Figure 3d), multiple AUC comparisons reveal that cocaine significantly increases $5-\mathrm{HT}_{\mathrm{ex}}$ in $\mathrm{DAT}+I+\mathrm{SERT}-I-$ and DAT $+I-\mathrm{SERT}-I-$ mice, but 

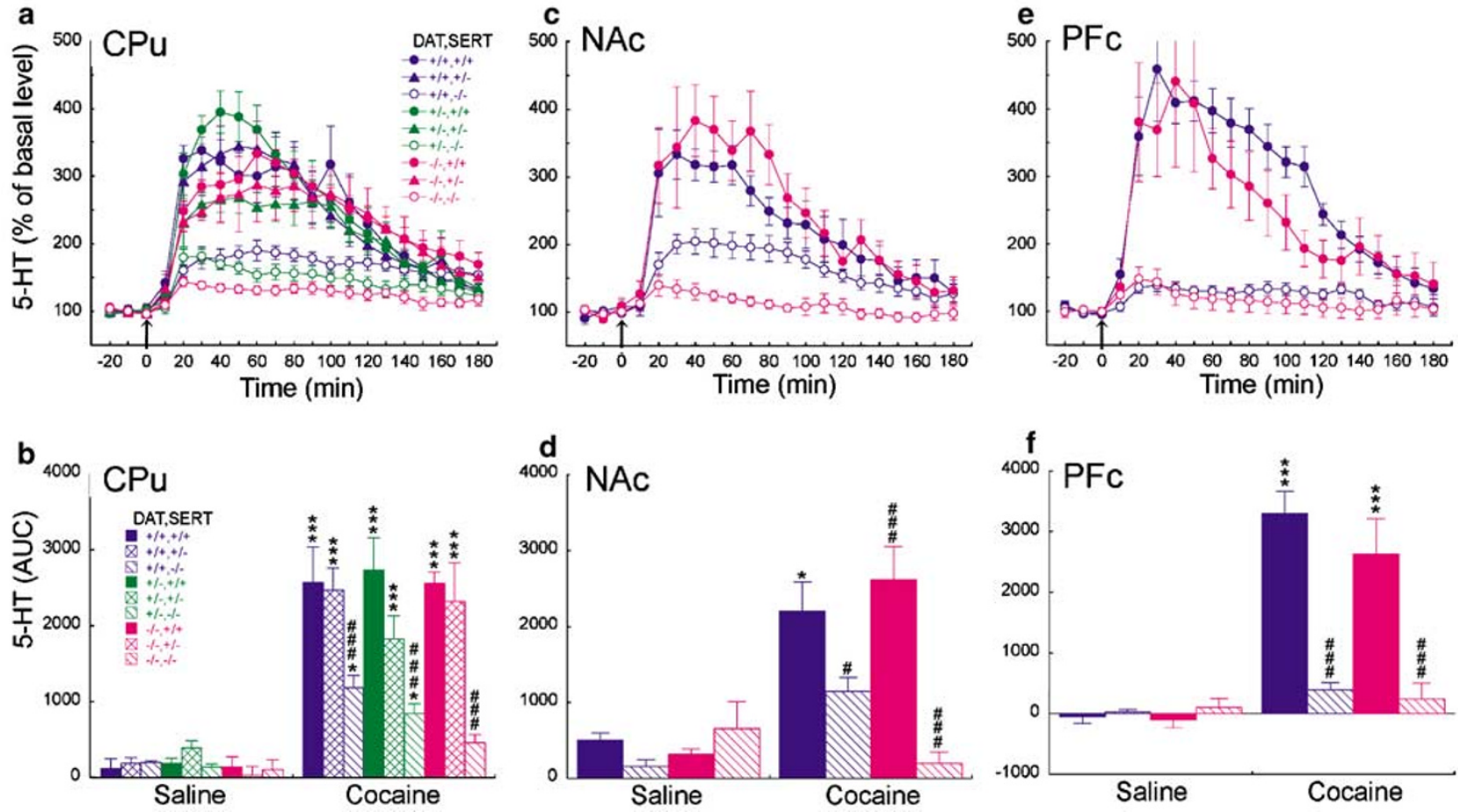

Figure 3 (a, c, and e) Temporal pattern of 5-HT response to cocaine $(10 \mathrm{mg} / \mathrm{kg}$, s.c.) in CPu, NAc, and PFc, respectively. The time of injections is indicated with an arrow. (b) Histogram represents the mean AUC ( \pm SEM) of 5-HT response to saline or cocaine in CPu, NAc, and PFc during the 180 min interval

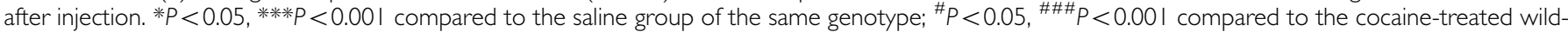
type group.

not in DAT-/-SERT $-/-$ mice. SERT $+/-$ mice display cocaine-induced increases in $5-\mathrm{HT}_{\mathrm{ex}}$ in $\mathrm{CPu}$ that are similar to those found in wild-type values. PFc 5-HT $\mathrm{Hx}_{\mathrm{ex}}$ levels are not altered significantly by cocaine in SERT $-/-$ mice (Figure 3f).

\section{Systemic Fluoxetine Effects on $\mathrm{DA}_{\mathrm{ex}}$ in $\mathrm{CPu}$ and NAc}

The temporal patterns of $\mathrm{DA}$ response to fluoxetine in $\mathrm{CPu}$ and NAc of DAT $+l+$ SERT $+l+$, DAT $-l-S E R T+l+$, $\mathrm{DAT}+I+\mathrm{SERT}-I-$, and $\mathrm{DAT}-I-\mathrm{SERT}-I-$ mice are shown in Figure $4 \mathrm{a}$ and $\mathrm{c}$. In $\mathrm{CPu}$ (Figure 4a), DAT-/$\mathrm{SERT}+/+$ mice exhibit gradual DA responses to fluoxetine that display time courses similar to those of cocaine and persist for at least $3 \mathrm{~h}$ (Figure 4a). Two-way ANOVAs of DA AUC responses show significant effects of Drug $(\mathrm{F}(1,33)=9.62, P<0.01)$ and Drug $\times$ Genotype interactions $(\mathrm{F}(1,33)=4.94, P<0.01)$. Multiple comparisons reveal that fluoxetine significantly increases DA AUC only in the $\mathrm{CPu}$ of DAT- $/-\mathrm{SERT}+I+$ mice (Figure $4 \mathrm{~b}$ ). In NAc, DA responses to fluoxetine display no significant effects of either Drug $(\mathrm{F}(1,29)=0.0076, P=0.93)$, Genotype $(\mathrm{F}(1,29)=0.49, \quad P=0.69), \quad$ genotype $\quad(\mathrm{F}(1,29)=0.69$, $P=0.41)$ or Drug $\times$ Genotype interaction $(\mathrm{F}(3,29)=1.55$, $P=0.22$ ) (Figure $4 \mathrm{~d}$ ).

\section{Systemic GBR12909 Effects on 5-HT $\mathrm{Hx}_{\mathrm{ex}}$ in CPu}

The temporal pattern of $\mathrm{CPu} 5-\mathrm{HT}$ response to GBR12909 is shown in Figure $5 \mathrm{a}$. DAT $+/+\mathrm{SERT}-/-$ mice exhibit remarkable $5-\mathrm{HT}_{\mathrm{ex}}$ increases after administration of GBR12909, which are not seen in WT mice. These SERT-
$\mathrm{KO}$ mice continue to display elevated $\mathrm{CPu} 5-\mathrm{HT}_{\mathrm{ex}}$ levels for at least $3 \mathrm{~h}$. Two-way ANOVA of the AUC of the DA response to GBR 12909 shows significant effects of Drug $(\mathrm{F}(1,13)=14.43, \quad P<0.01), \quad$ Genotype $\quad(\mathrm{F}(1,13)=7.63$, $P<0.05)$, and Drug $\times$ Genotype interactions $(\mathrm{F}(1,13)=$ 5.74, $P<0.05)$. Multiple comparisons show that GBR12909 administration significantly increases $\mathrm{CPu} 5-\mathrm{HT}_{\mathrm{ex}}$ in $\mathrm{DAT}+I+$ SERT $-I-$, but not in wild-type mice (Figure $5 \mathrm{~b}$ ).

\section{Local Cocaine Effects on $\mathrm{DA}_{\mathrm{ex}}$ and $5-\mathrm{HT}_{\mathrm{ex}}$ in $\mathrm{CPu}$}

$\mathrm{DA}_{\mathrm{ex}}$ and $5-\mathrm{HT}_{\mathrm{ex}}$ level changes in $\mathrm{CPu}$ following local cocaine infusion are shown in Figure $6 \mathrm{a}$ and $\mathrm{c}$. Local cocaine cannot induce $\mathrm{DA}$ response curve in $\mathrm{CPu}$ of $\mathrm{DAT}-/-$ SERT $+I+$ and DAT $-I-$ SERT $-I-$ mice, but produces gradual 5-HT response curve in DAT $+I+$ SERT $-I-$ mice.

ANOVAs of mean AUC $( \pm S E M)$ for DA responses reveal significant effects of Drug, Genotype, and Drug $\times$ Genotype interactions in $\mathrm{CPu} \quad(\mathrm{F}(1,24)=161.46, \quad P<0.0001$; $\mathrm{F}(3,24)=48.20, \quad P<0.0001 ; \quad \mathrm{F}(3,24)=47.30, \quad P<0.0001$; respectively). Multiple AUC comparisons show that local cocaine fails to increase $\mathrm{DA}_{\mathrm{ex}}$ in $\mathrm{CPu}$ of $\mathrm{DAT}-/-$ $\mathrm{SERT}+/+$ or in DAT- $/-\mathrm{SERT}-/-$ mice (Figure 6b). ANOVAs of mean AUC $( \pm S E M)$ for 5 -HT responses also reveal significant effects of Drug, Genotype, and Drug $\times$ Genotype interactions in $\mathrm{CPu}(\mathrm{F}(1,24)=43.26$, $P<0.0001 ; \quad \mathrm{F}(3,24)=9.55, \quad P<0.0001 ; \quad \mathrm{F}(3,24)=9.70$, $P<0.0001$; respectively). Multiple comparisons reveal that local cocaine significantly increases $5-\mathrm{HT}_{\mathrm{ex}}$ in wild-type, $\mathrm{DAT}+I+\mathrm{SERT}-I-$ and $\mathrm{DAT}-I-\mathrm{SERT}+I+$ mice, but not in DAT $-/-$ SERT $-/-$ mice (Figure $6 \mathrm{~d}$ ). Moreover, there were no significant changes in $\mathrm{NAc}_{\mathrm{DA}}$ in $\mathrm{DAT}-/-$ 

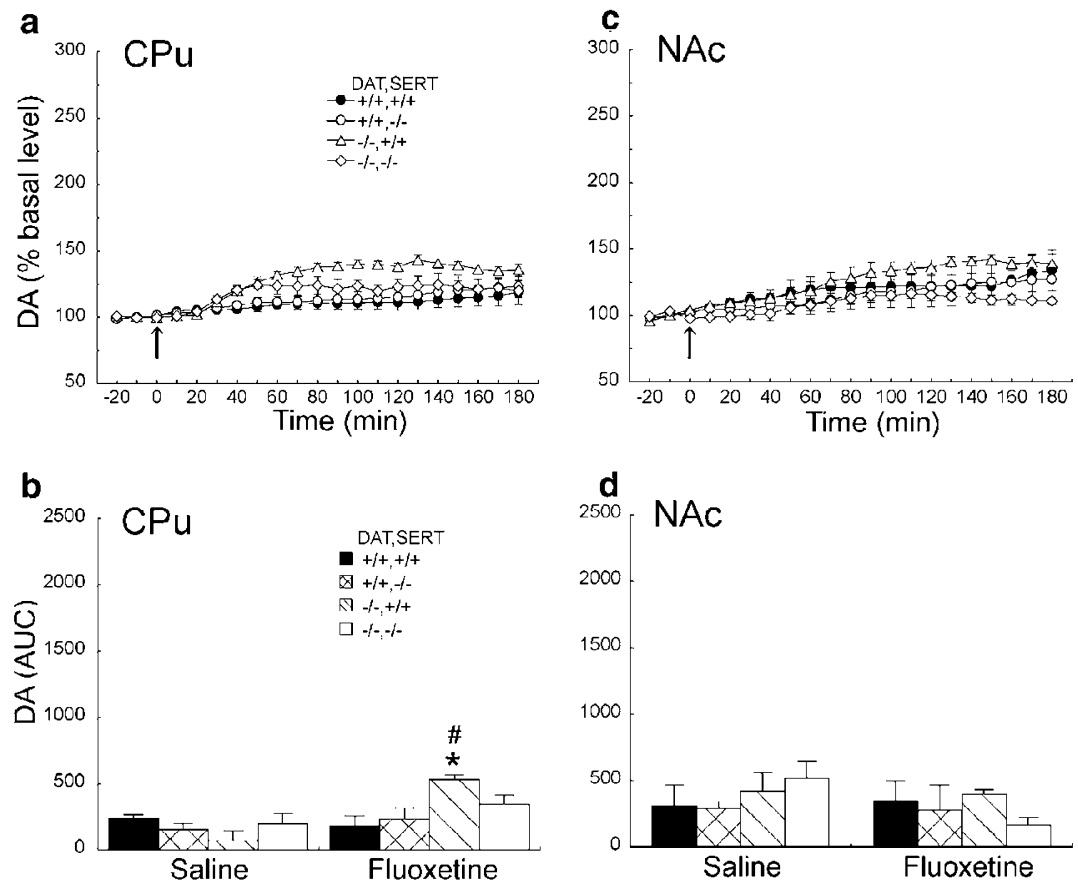

Figure 4 (a and c) Temporal pattern of DA response to fluoxetine $(20 \mathrm{mg} / \mathrm{kg}$, s.c.) in CPu and NAc, respectively. The time of injections is indicated with an arrow. (b and d) The histogram represents the mean AUC ( \pm SEM) of DA response to saline or fluoxetine in CPu and NAc during the I80 min interval after injection. $* P<0.05$ compared to the saline group of the same genotype; ${ }^{\#} P<0.05$ compared to the fluoxetine-treated wild-type group.
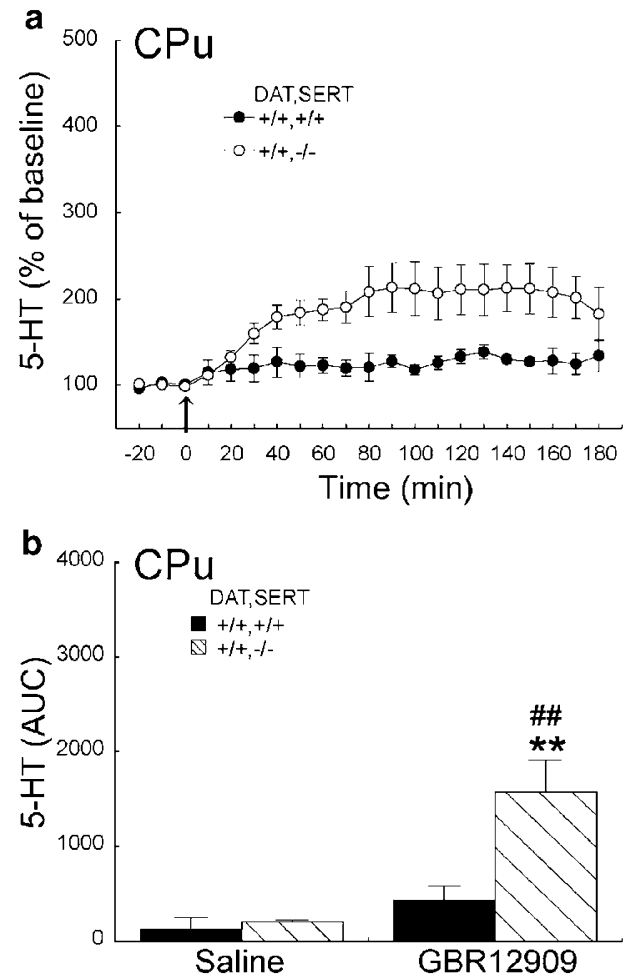

Figure 5 (a) Temporal pattern of 5-HT response to GBRI 2909 ( 10 mg/ $\mathrm{kg}$, s.c.) in CPu. The time of injections is indicated with an arrow. (b) The histogram represents the mean $\mathrm{AUC}( \pm \mathrm{SEM})$ of $5-\mathrm{HT}$ response to saline or GBRI2909 in CPu during 180 min interval after injection. $* * P<0.01$ compared to the saline group of the same genotype; ${ }^{\#} P<0.01$ compared to the GBRI2909-treated wild-type group.
SERT $+I+$ and DAT $-I-$ SERT $-I-$ mice after local cocaine infusions (data not shown).

\section{DISCUSSION}

These microdialysis results reveal parallels with and differences from the patterns of $\mathrm{KO}$ effects on reward elicited by cocaine and fluoxetine that we have previously reported in these mouse strains. We can thus evaluate hypotheses about the pharmacological profiles and brain localization of processes hypothesized to mediate cocaine reward with regard to their convergence or divergence with this microdialysis data.

Differential DA Responses in to Cocaine in $\mathrm{CPu}$, NAc, and PFC and Correlations with Assessments of Cocaine Reward

The current data do not provide simple correlations with models that postulate that enhanced $\mathrm{NAc}_{\mathrm{DA}}$ levels alone are necessary and sufficient for cocaine reward. Although this hypothesis has been supported by data from microinjection and lesion studies (Kuhar et al, 1991; Koob and Nestler, 1997; Bardo, 1998; Kelley and Berridge, 2002), many results from gene $\mathrm{KO}$ studies fail to support the simple hypothesis that DA alone mediates the rewarding effects of cocaine. Our current observations that cocaine does not increase $\mathrm{DA}_{\mathrm{ex}}$ in NAc of homozygous DAT-KO mice contrasts with the nearly-intact cocaine reward found in these animals (Rocha et al, 1998; Sora et al, 1998). These in vivo microdialysis data are also consistent with studies which document failure of cocaine to block DA uptake in 

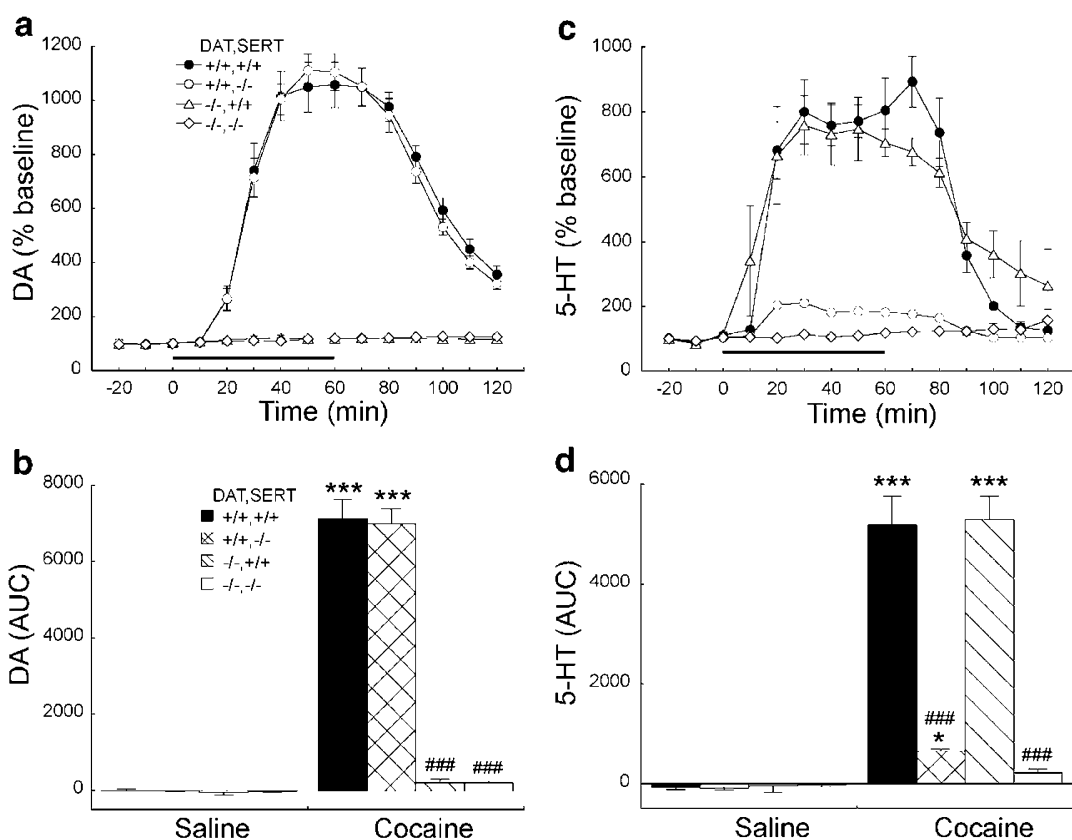

Figure 6 (a and c) Temporal pattern of DA and 5-HT response to local cocaine infusion ( $100 \mu \mathrm{M})$ in CPu, respectively. Horizontal bar indicates the time of infusions. ( $b$ and d) The histogram represents the mean AUC ( \pm SEM) of DA and 5-HT response to saline or cocaine in CPu during 120 min interval after injection. ${ }^{*} P<0.05$, ${ }^{* * *} P<0.00$ I compared to the saline group of the same genotype; ${ }^{\# \#} P<0.00$ I compared to the cocaine-treated wild-type group.

NAc samples taken from DAT homozygous mice in in vitro experiments (Budygin et al, 2002; Moron et al, 2002).

The current data also fail to provide simple correlations with models that postulate that enhanced PFc DA levels are necessary and sufficient for cocaine reward. This hypothesis has also been supported by a substantial body of lesion and microinjection data (Goeders and Smith, 1983; Goeders et al, 1986; Bardo, 1998; Tzschentke, 2001). Cocaine increases $\mathrm{DA}_{\mathrm{ex}}$ in PFc of both wild-type and homozygous DAT-KO mice that exhibit cocaine reward and DAT/SERT double homozygous $\mathrm{KO}$ mice that do not display cocaine reward.

Intriguingly, the current results for $\mathrm{DA}$ in $\mathrm{CPu}$ appear to provide the best fit with studies of cocaine-induced place preferences. Although intra- $\mathrm{CPu}$ cocaine does not affect $\mathrm{DA}_{\text {ex }}$ levels in DAT-KO mice, systemic cocaine causes about 1.5-fold increase in peak $\mathrm{DA}_{\mathrm{ex}}$ concentrations in $\mathrm{CPu}$ dialysate from DAT-KO mice that are rewarded by cocaine, but not from DAT/SERT double homozygous KO mice that lack cocaine CPP. Systemic fluoxetine also increases $\mathrm{CPu}$ $\mathrm{DA}_{\mathrm{ex}}$ levels in homozygous DAT-KO mice in which this compound is rewarding, but not in wild-type mice or homozygous SERT-KO mice in which fluoxetine does not produce a place preference.

\section{Differential 5-HT Responses to Cocaine in $\mathrm{CPu}, \mathrm{NAc}$, and $\mathrm{PFC}$ and Correlations with Assessments of Cocaine Reward}

Although cocaine-induced increases in $\mathrm{CPu}$ and NAc $5-\mathrm{HT}_{\mathrm{ex}}$ are found in SERT-KO mice that exhibit enhanced cocaine CPP, the magnitude of the increases in $5-\mathrm{HT}_{\mathrm{ex}}$ after cocaine administration is attenuated when it is compared with wild-type mice. Interestingly, chronic SERT blockade with fluoxetine can also potentiate cocaine reward (Cun- ningham and Callahan, 1991; Kleven and Koek, 1998). It is conceivable that the attenuation of cocaine-induced $5-\mathrm{HT}_{\mathrm{ex}}$ rise may lead mice more sensitive to the reward effect of cocaine. These sorts of data, and the current results, continue to point to possible roles for 5-HT in cocaine reward, especially in light of the more complex hypotheses of the basis of cocaine reward discussed below.

\section{5-HT $\mathrm{Hx}_{\text {ex }}$ Clearance by DAT, $\mathrm{DA}_{\mathrm{ex}}$ Clearance by NET, and} opportunities for 'Promiscuous Uptake'

Removal of a transporter that usually provides inactivation, re-accumulation, and recycling of a released monoamine neurotransmitter provides opportunities for greater diffusion of the monoamine, documented by higher extracellular dialysate concentrations noted here. Removal of a cognate transporter also enhances the opportunities for transmitter uptake by a transporter that normally recognizes another monoamine. The presence of the same vesicular transporter in DAT-, SERT-, and NET-expressing neurons provides the opportunity for the monoamine that has been taken up by a non-cognate plasma membrane transporter to be accumulated into vesicles, and to be re-released as a 'false transmitter' (Liu and Edwards, 1997; Uhl et al, 2000). DA accumulation by NET-expressing neurons also provides the opportunity for DA to be subjected to $\beta$-hydroxylation to produce norepinephrine, providing a 'true' transmitter for noradrenergic neurons. It is interesting to note that elimination of monoamine transporters has different effects on basal monoamine levels in different brain regions, supporting ideas that factors that mediate DA and 5-HT clearance from synaptic clefts may differ substantially from one terminal field to another. 
Many of the present and previously reported results appear to provide evidence for uptake by non-cognate transporters, and even for possible 'false transmission' in these transporter-KO mice. Cocaine and the selective DAT blocker GBR12909 produces a substantial increase in dialysate 5-HT in SERT-KO mice that is not found in wild-type animals. These findings were supported by previous reports that have documented 5-HT uptake by cultured neurons from SERT-KO mice that could be blocked by selective DAT blockers (Pan et al, 2001), and 5 -HT-like immunoreactivity in substantia nigra and ventral tegmental area dopaminergic neurons (Zhou et al, 2002). False transmission may be region-dependent, with differences in the relative densities of DAT- SERT- and NET-expressing neural elements providing differential opportunities for such processes.

Moreover, our observations of virtually identical PFc $\mathrm{DA}_{\text {ex }}$ baselines in each of these KO strains appear to support a relatively reduced prominence of DAT-mediated DA uptake in this region even in wild-type mice. These observations are compatible with the relatively sparse distribution of PFc DAT in several species (Freed et al, 1995; Sesack et al, 1998), in contrast with more prominent NET and SERT expression. They are also in accord with pharmacological and other evidence for significant NETmediated DA uptake in rodent PFc (Di Chiara et al, 1992; Tanda et al, 1997; Yamamoto and Novotney, 1998). DA may thus be accumulated by NET in PFc of both wild-type and DAT-KO mice.

The current observations in DA response to cocaine and fluoxetine in $\mathrm{CPu}$ of DAT-KO mice may provide a different picture. Although systemic cocaine and fluoxetine increase significantly $\mathrm{CPu} \mathrm{DA}_{\mathrm{ex}}$ in DAT-KO mice, local cocaine fails to change it. These results demonstrate that SERT does nt play a role of 'promiscuous uptake' in DA clearance. Systemic cocaine- or fluoxetine-induced DA increase in $\mathrm{CPu}$ of DAT-KO mice may result from DA release from activated DA neuron rather than local clearance by SERT.

\section{Comparisons with Other Results}

Observations that $\mathrm{CPu}$ dialysate monoamine levels apparently provide the best parallel with the loss of cocaine CPP found in current results could be consistent with a previously underappreciated role for $\mathrm{CPu}$ structures in mediating some of the 'learned' features of cocaine reward that are manifest in conditioned place preference testing (White and McDonald, 2002). These structures can be critical for stimulus-response 'habit' learning, including that related to reward (Jog et al, 1999; Reynolds et al, 2001). It is conceivable that this structure may play an even greater role in DAT-KO mice that lack cocaine-induced $\mathrm{DA}_{\mathrm{ex}}$ elevations in NAc.

The failure of dialysis results for DA alone in NAc or PFc to parallel cocaine reward effects of various KOs and the apparent parallel in $\mathrm{CPu}$ should not prevent further consideration of: (a) multiple compensating contributions of monoamines to the rewarding effects of cocaine; (b) contributions of cocaine effects on monoamines in other brain regions, for example, ventral pallidum (Gong et al, 1996, 1997), ventral tegmental area (Roberts and Koob, 1982; Ranaldi and Wise, 2001) for cocaine reward; (c) effects of nonmonoaminergic adaptations to the retained cocaine reward in the transporter $\mathrm{KO}$ mouse strains that retain such reward. Monoamine actions in brain regions such as the ventral tegmental area have been postulated to be central to the rewarding actions of major drug classes, such as opiates (Wise, 1989; Garzon and Pickel, 2001) and stimulants. It is quite conceivable that monoamine actions in areas not sampled in the current studies could play roles in normal cocaine reward mechanisms, and in adaptations that may underlie the retention of cocaine reward in DAT- and in SERT-KO mice. Mice with single or multiple transporter deletions display many adaptive alterations, as assessed through behavioral, neurochemical, per- or post-synaptic receptor binding, gene expression, and other analytical approaches. None of the current data should hinder attempts to add more explanatory power for the remarkable behavioral pharmacological profiles displayed by these KO mice through use of any or all of these alternative approaches.

The current results in $\mathrm{NAc}$ and $\mathrm{CPu} \mathrm{DA}$ response to cocaine in DAT-KO mice produced in our laboratory, while highly reproducible in our hands, differ from those obtained in reports from another line of DAT-KO mice that which showed that systemic cocaine and reboxetine (NET blocker) increased $\mathrm{DA}_{\mathrm{ex}}$ remarkably in NAc of DATKO mice (Carboni et al, 2001). The different DA response to cocaine in NAc and CPu between Carboni's and our DAT KOs may be due to the different DNA construction which was used to disrupt DAT gene. Moreover, our findings are consistent with other reports which demonstrated that cocaine could not affect DA clearance in NAc of DAT-KO mice via in vitro experiments. It is noteworthy that (1) $\mathrm{DA}_{\mathrm{ex}}$ baseline in NAc of DAT-KO mice is about 10 times greater than that in wild-type mice, and that (2) the capacity for DA uptake of NET is far weaker than that of DAT (Giros et al, 1994; Gu et al, 1994). These may be the reasons why NET cannot show redundancy for DAT in NAc.

In summary, the present work adds to previous data concerning the behavioral consequences of DAT and SERT deletion, by suggesting that cocaine CPP does not necessarily correlate with simple elevations of DA the NAc or PFc. It points out unanticipated correlations with $\mathrm{DA}_{\mathrm{ex}}$ elevations in $\mathrm{CPu}$. It is interesting that the $\mathrm{CPu}$ findings parallel behavioral observations of the rewarding profiles of not only cocaine but also of fluoxetine in these varying mouse strains. While these correlations do not prove causation, the data support careful re-examination of $\mathrm{CPu}$ roles in psychostimulant reward (or reward learning) in both wild-type and DAT-KO mice, including both the dorsal and ventral $\mathrm{CPu}$ regions likely to be sampled with our microdialysis approaches. Another view of the current results is that the double homozygous DAT/SERT combined $\mathrm{KO}$ mice that failed to display either cocaine-induced $\mathrm{DA}_{\mathrm{ex}}$ or $5-\mathrm{HT}_{\mathrm{ex}}$ elevations in NAc also failed to exhibit cocaine $\mathrm{CPP}$, suggesting perhaps that either $\mathrm{DA}_{\mathrm{ex}}$ or $5-\mathrm{HT}_{\mathrm{ex}}$ elevation can mediate cocaine reward and that the absence of both effects is required to eliminates the cocaine CPP. The current data also add to the growing body of evidence that may indicate uptake of released monoamines by noncognate transporters when their cognate transporters are deleted, and provide evidence for the brain-region specificity of these processes in wild-type and in transporter $\mathrm{KO}$ 
mice. Each of these findings adds pieces to the complex puzzle of the mediation of cocaine reward by monoaminergic brain systems.

\section{ACKNOWLEDGEMENTS}

This work was supported by Grants-in-Aid from MECSST and Health Sciences Research Grants from MHLW, Japan, and NIDA-IRP, USA.

\section{REFERENCES}

Baker DA, Tran-Nguyen TL, Fuchs RA, Neisewander JL (2001). Influence of individual differences and chronic fluoxetine treatment on cocaine-seeking behavior in rats. Psychopharmacology (Berl) 155: 18-26.

Bardo MT (1998). Neuropharmacological mechanisms of drug reward: beyond dopamine in the nucleus accumbens. Crit Rev Neurobiol 12: 37-67.

Budygin EA, John CE, Mateo Y, Jones SR (2002). Lack of cocaine effect on dopamine clearance in the core and shell of the nucleus accumbens of dopamine transporter knock-out mice. J Neurosci 22: RC222.

Carboni E, Spielewoy C, Vacca C, Nosten-Bertrand M, Giros B, Di Chiara G (2001). Cocaine and amphetamine increase extracellular dopamine in the nucleus accumbens of mice lacking the dopamine transporter gene. J Neurosci 21(RC141): 141-144.

Cunningham KA, Callahan PM (1991). Monoamine reuptake inhibitors enhance the discriminative state induced by cocaine in the rat. Psychopharmacology (Berl) 104: 177-180.

Di Chiara G, Tanda GL, Frau R, Carboni E (1992). Heterologous monoamine reuptake: lack of transmitter specificity of neuronspecific carriers. Neurochem Int 20(Suppl): 231S-235S.

Eshleman AJ, Carmolli M, Cumbay M, Martens CR, Neve KA, Janowsky A (1999). Characteristics of drug interactions with recombinant biogenic amine transporters expressed in the same cell type. J Pharmacol Exp Ther 289: 877-885.

Faraj BA, Olkowski ZL, Jackson RT (1994). Active [3H]-dopamine uptake by human lymphocytes: correlates with serotonin transporter activity. Pharmacology 48: 320-327.

Franklin KBJ, Paxinos G (1997). The Mouse Brain in Stereotaxic Coordinates. Academic: San Diego.

Freed C, Revay R, Vaughan RA, Kriek E, Grant S, Uhl GR et al (1995). Dopamine transporter immunoreactivity in rat brain. $J$ Comp Neurol 359: 340-349.

Garzon M, Pickel VM (2001). Plasmalemmal mu-opioid receptor distribution mainly in nondopaminergic neurons in the rat ventral tegmental area. Synapse 41: 311-328.

Giros B, Wang YM, Suter S, McLeskey SB, Pifl C, Caron MG (1994). Delineation of discrete domains for substrate, cocaine, and tricyclic antidepressant interactions using chimeric dopaminenorepinephrine transporters. J Biol Chem 269: 15985-15988.

Goeders NE, Dworkin SI, Smith JE (1986). Neuropharmacological assessment of cocaine self-administration into the medial prefrontal cortex. Pharmacol Biochem Behav 24: 1429-1440.

Goeders NE, Smith JE (1983). Cortical dopaminergic involvement in cocaine reinforcement. Science 221: 773-775.

Gong W, Neill D, Justice Jr JB (1996). Conditioned place preference and locomotor activation produced by injection of psychostimulants into ventral pallidum. Brain Res 707: 64-74.

Gong W, Neill D, Justice Jr JB (1997). 6-Hydroxydopamine lesion of ventral pallidum blocks acquisition of place preference conditioning to cocaine. Brain Res 754: 103-112.

$\mathrm{Gu}$ H, Wall SC, Rudnick G (1994). Stable expression of biogenic amine transporters reveals differences in inhibitor sensitivity, kinetics, and ion dependence. J Biol Chem 269: 7124-7130.
Hall FS, Li XF, Sora I, Xu F, Caron M, Lesch KP et al (2002). Cocaine mechanisms: enhanced cocaine, fluoxetine and nisoxetine place preferences following monoamine transporter deletions. Neuroscience 115: 153-161.

Jog MS, Kubota Y, Connolly CI, Hillegaart V, Graybiel AM (1999). Building neural representations of habits. Science 286: 1745-1749.

Kelley AE, Berridge KC (2002). The neuroscience of natural rewards: relevance to addictive drugs. J Neurosci 22: 3306-3311.

Kirkpatrick P (2001). A rewarding double act. Nature Reviews Neuroscience 3: 284.

Kleven M, Ybema C, Carilla E, Hamon M, Koek W (1995). Modification of behavioral effects of 8-hydroxy-2-(di-n-propylamino)tetralin following chronic ethanol consumption in the rat: evidence for the involvement of 5-HT1A receptors in ethanol dependence. Eur J Pharmacol 281: 219-228.

Kleven MS, Koek W (1998). Discriminative stimulus properties of cocaine: enhancement by monoamine reuptake blockers. J Pharmacol Exp Ther 284: 1015-1025.

Koob GF, Nestler EJ (1997). The neurobiology of drug addiction. J Neuropsychiatry Clin Neurosci 9: 482-497.

Kuhar MJ, Ritz MC, Boja JW (1991). The dopamine hypothesis of the reinforcing properties of cocaine. Trends Neurosci 14: 299-302.

Lee K, Kornetsky C (1998). Acute and chronic fluoxetine treatment decreases the sensitivity of rats to rewarding brain stimulation. Pharmacol Biochem Behav 60: 539-544.

Liu Y, Edwards RH (1997). The role of vesicular transport proteins in synaptic transmission and neural degeneration. Annu Rev Neurosci 20: 125-156.

Moron JA, Brockington A, Wise RA, Rocha BA, Hope BT (2002). Dopamine uptake through the norepinephrine transporter in brain regions with low levels of the dopamine transporter: evidence from knock-out mouse lines. J Neurosci 22: 389-395.

Pan Y, Gembom E, Peng W, Lesch KP, Mossner R, Simantov R (2001). Plasticity in serotonin uptake in primary neuronal cultures of serotonin transporter knockout mice. Brain Res Dev Brain Res 126: 125-129.

Parsons LH, Weiss F, Koob GF (1998). Serotonin1B receptor stimulation enhances cocaine reinforcement. J Neurosci 18: 10078-10089.

Ranaldi R, Wise RA (2001). Blockade of D1 dopamine receptors in the ventral tegmental area decreases cocaine reward: possible role for dendritically released dopamine. J Neurosci 21: 5841-5846.

Reynolds JN, Hyland BI, Wickens JR (2001). A cellular mechanism of reward-related learning. Nature 413: 67-70.

Roberts DC, Koob GF (1982). Disruption of cocaine selfadministration following 6-hydroxydopamine lesions of the ventral tegmental area in rats. Pharmacol Biochem Behav 17: 901-904.

Rocha BA, Ator R, Emmett-Oglesby MW, Hen R (1997). Intravenous cocaine self-administration in mice lacking 5HT1B receptors. Pharmacol Biochem Behav 57: 407-412.

Rocha BA, Fumagalli F, Gainetdinov RR, Jones SR, Ator R, Giros B et al (1998). Cocaine self-administration in dopamine-transporter knockout mice. Nat Neurosci 1: 132-137.

Sasaki-Adams DM, Kelley AE (2001). Serotonin-dopamine interactions in the control of conditioned reinforcement and motor behavior. Neuropsychopharmacology 25: 440-452.

Sesack SR, Hawrylak VA, Matus C, Guido MA, Levey AI (1998). Dopamine axon varicosities in the prelimbic division of the rat prefrontal cortex exhibit sparse immunoreactivity for the dopamine transporter. J Neurosci 18: 2697-2708.

Shippenberg TS, Hen R, He M (2000). Region-specific enhancement of basal extracellular and cocaine-evoked dopamine levels following constitutive deletion of the Serotonin(1B) receptor. J Neurochem 75: 258-265. 
Sora I, Hall FS, Andrews AM, Itokawa M, Li XF, Wei HB et al (2001). Molecular mechanisms of cocaine reward: combined dopamine and serotonin transporter knockouts eliminate cocaine place preference. Proc Natl Acad Sci USA 98: 5300-5305.

Sora I, Wichems C, Takahashi N, Li XF, Zeng Z, Revay R et al (1998). Cocaine reward models: conditioned place preference can be established in dopamine- and in serotonin-transporter knockout mice. Proc Natl Acad Sci USA 95: 7699-7704.

Tanda G, Pontieri FE, Frau R, Di Chiara G (1997). Contribution of blockade of the noradrenaline carrier to the increase of extracellular dopamine in the rat prefrontal cortex by amphetamine and cocaine. Eur J Neurosci 9: 2077-2085.

Tzschentke TM (2001). Pharmacology and behavioral pharmacology of the mesocortical dopamine system. Prog Neurobiol 63: 241-320.
Uhl GR, Hall FS, Sora I (2002). Cocaine, reward, movement and monoamine transporters. Mol Psychiatry 7: 21-26.

Uhl GR, Li S, Takahashi N, Itokawa K, Lin Z, Hazama M et al (2000). The VMAT2 gene in mice and humans: amphetamine responses, locomotion, cardiac arrhythmias, aging, and vulnerability to dopaminergic toxins. Faseb J 14: 2459-2465.

White NM, McDonald RJ (2002). Multiple parallel memory systems in the brain of the rat. Neurobiol Learn Mem 77: 125-184.

Wise RA (1989). Opiate reward: sites and substrates. Neurosci Biobehav Rev 13: 129-133.

Yamamoto BK, Novotney S (1998). Regulation of extracellular dopamine by the norepinephrine transporter. J Neurochem 71: 274-280.

Zhou FC, Lesch KP, Murphy DL (2002). Serotonin uptake into dopamine neurons via dopamine transporters: a compensatory alternative. Brain Res 942: 109-119. 